but no change in the names or number of the Sections are recommended apart from the formation of a new Section corresponding with the Assembly of Corresponding Societies in the British Association. Stress is laid on keeping the public informed on what science is doing as the primary function of the Association and the report recommends that as much sectional time as possible should be devoted to meetings of the symposium type which present more general matters from several angles.

Journal of Medicinal and Pharmaceutical Chemistry

This new journal (1, No. 1, February 1959. Pp. 120. Published bi-monthly; subscription price $115 \mathrm{~s}$. or 15 dollars per annual volume including postage. New York: Interscience Publishers, Inc.; London: Interscience Publishers, Ltd., 1959) will be mainly of interest to the synthetic chemist engaged in the manufacture of drugs and to pharmaceutical chemists and pharmacologists whose line of research lies in the drug-action relationship. "Chemicalbiological correlative work" is defined by the editors as one of the main fields which the new journal wishes to cover. Papers are to be accepted in English, French or German. The increasing number of drugs produced by the chemical industry, all of which need biological evaluation, probably created a need for a special journal to deal with the quantity of work done; the future will show whether this need could not have been covered by the existing journals.

\section{Commonwealth Bursaries Scheme}

THE fifth annual report on the Royal Society and Nuffield Foundation Commonwealth Bursaries Scheme covers the year ended December 31, 1958 (pp. 8. London: Royal Society and Nuffield Foundation, 1959), in which 26 bursaries, totalling $£ 13,974$, were offered, compared with 18 , totalling $£ 8,423$, in 1957 . Of these 8 were for visits from the United Kingdom, 12 for visits to the United Kingdom and 3 for visits between countries of the Commonwealth other than the United Kingdom; three offers were not accepted. Of the 67 applications considered during the year, 44 were for visits to the United Kingdom, 11 for visits from the United Kingdom and 12 for visits between Commonwealth countries other than the United Kingdom. Most of the applications were of a high standard. Besides the Nuffield Foundation's grant of $£ 5,000$, which was received for 5 years from $1959, £ 2,000$ was received through a Parliamentary Grant-in-aid to the Royal Society, $£ 1,200$ from Canada, $£ 800$ from Australia, $£ 400$ from South Africa, $£ 32210$ s. from Pakistan, $£ 200$ from New Zealand, and $£ 100$ each from Ceylon, Rhodesia and Nyasaland.

\section{Studies in Indonesia}

The Jajasan Siswa Lokantara, the local Indonesian foundation for granting fellowships to foreigners studying in the country, is ready to consider suitably qualified applicants in any subject of study. This foundation has considerable funds at its disposal and is independent of government departments; it is prepared to guarantee all reasonable local expenses, including living costs and fares within Indonesia, but owing to the considerable variations in cost of living throughout the territory has refrained from fixing a definite monthly allowance. The intention is to operate a flexible and reasonably generous allowance scheme which will enable Fellows to study where they wish (so far as internal conditions and transport facilities allow), and to establish close relations with Indonesians working in similar fields. Further information can be obtained from the Universities Section, Education Division, British Council, 65 Davies Street, London, W.1.

\section{First All-India Congress of Zoology}

The first All-India Congress of Zoology, sponsored by the Zoological Society of India, which was to have been held last year but was postponed, will be held at Jabalpur during October 24-29, at the invitation of the University of Jabalpur. Further information can be obtained from the General Secretary, Dr. B.S. Chauhan, c/o Zoological Survey of India, 34 Chittaranjan Avenue, Calcutta 12.

\section{Announcements}

Dr. A. A. Moss has been appointed deputy keeper of the Department of Mineralogy in the British Museum (Natural History).

Prof. John ReAD, professor of chemistry in the University of St. Andrews, has been selected for the 1959 Dexter Award which is administered by the Division of History of Chemistry of the American Chemical Society.

Dr. H. Albert Barker, professor of microbial biochemistry in the University of California, Berkeley, has been awarded the Neuberg Medal for outstanding work in biochemistry and, in particular, for his discovery of the coenzyme corresponding to vitamin $\mathrm{B}_{12}$. The Neuberg Medal was created to honour Carl Neuberg, a pioneer in biochemistry. It is given annually by the American Society of European Chemists for outstanding contributions in the field of biochemistry.

AN International Congress on Radiology will be held in Munich during July 23-30. Further information can be obtained from the CongressSekretariat, Reitmorstrasse 29, Munich 22.

A symposium on Fluorine Chemistry is being arranged under the auspices of the Chemical Society, to be held in the University of Birmingham during July $15-17$, covering topics in organic, inorganic and physical chemistry. Further details ean be obtained from the Secretary, Fluorine Symposium, Chemistry Department, The University, Edgbaston, Birmingham 15.

THE twenty-first International Congress of Physiological Sciences (Physiology and Pharmacology) will be held in Buenos Aires during August 9-15 under the presidency of Prof. Bernardo A. Houssay. Further information can be obtained from the Secretary, Twenty-first International Congress of Physiological Sciences, Facultad de Ciencias Médicas, Paraguay 2151, Buenos Aires, Argentina.

THE Gordon Research Conferences for 1959 will be held during June 15-September 4 at Colby Junior College, New London, New Hampshire; New Hampton School, New Hampton, New Hampshire; and Kimball Union Academy, Meriden, New Hampshire. The conferences were established to stimulate research in universities, research foundations and industrial laboratories. This purpose is achieved by an informal type of meeting consisting of scheduled lectures and discussion groups. Further information can be obtained from W. George Parks, Director, Department of Chemistry, University of Rhode Island, Kingston, Rhode Island ; after June 15 from Colby Junior College, New London, New Hampshire. 